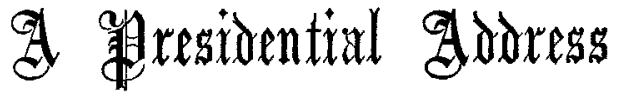

\section{THE PROGRESS OF SURGICAL METHODS.}

\author{
Read before the North of England Obstetrical and
} Gynacological Society on Dec. 20th, 1901,

By T. B. GRIMSDALE, B.A., M.B. Cantab., GYNACOLOGICAL SURGEON TO THE LIVERPOOT ROYAL INFIRMARY.

GENTLEMEN,-My first duty is to thank you for the honour which you have done me in electing me to be your president. I need hardly say that it is an honour which I appreciate very highly; and since you have made me your president there is a pleasant duty which devolves upon me, and that is to address you on some subject connected with gynæcology. It is unusual at such a time for the reader of the address to be interfered with or criticised, so that the president can say what he likes without much fear of contradiction. This, of course, is a great distinction and at times it may be felt to be a great advantage ; it at least shows the trust and confidence which the society has in its presidents, but as we all have the same object at heart, the advancement of gynæcology, I think that it is rather a pity that criticism, tempered with leniency, is not the rule. On this occasion if any one of my audience feels inclined to criticise my remarks, although it would be contrary to precedent, I shall not rule him out of order but shall take it as a compliment and a sign that $I$ have managed to interest him.

In casting about for a subject on which to address you I have not looked very far afield. I have taken the subject which appears to me to be the most important and which looms largest in the mind of the operating surgeon. It is the Progress of Surgical Methods-one might almost say the revolution in surgery. This is a theme upon which much has been written, and although I can hardly hope to add anything to this great subject, yet, however feeble my tribute, I feel that I must lay my homage at the feet of the great master of our art, Lord Lister, and pay reverence to the memory of that great Frenchman, Pasteur, from whom Lister's first inspiration was derived. When one considers the anxieties, the nervous strain, the bitter disappointments of the earlier surgeon, the horrible sufferings of the patient, which were sufficient to make the life of the surgeon a terrible ordeal such as few could endure, one cannot help feeling a spirit of devout thankfulness for the privilege of having lived after Lister's epoch-making discoveries.

There are three stages in the progress of surgical methods which I propose to touch upon; they are very striking and are significant of the theory of the method of healing of the day. These three stages are: (1) the open method period; (2) the drainage-tube or vent period; and (3) the period of complete closure. These three stages, of course, correspond with the pre-antiseptic, the antiseptic, and the aseptic periods. In the first of these periods suppuration was supposed to be inevitable and was encouraged by the surgeon. It was considered that the wound must be "digested" before it could heal and the wound was left open to accord with this theory. In the second period suppuration was expected and a vent was left for its exit. In the third period the presence of suppuration denoted failure. It was not expected and the wound was completely closed.

As illustrating the results obtained during the first period, when the open method of treatment was in vogue, $I$ will quote the results of amputations performed about 100 years ago, as stated by Alanson, one of the members of the staff of the Liverpool Royal Infirmary at that time. Alanson was a man of great originality, a most careful and successful surgeon, and an observer of great intelligence. He was much in advance of his time and was the inventor of "flaps" in the amputation of limbs. He says :-

Of 46 amputations at which I was present and had the opportunity of inspecting the after-treatment, 10 died; one of the lockjaw; two of hæmorrhage from the whole surface of the stump; four from the hectic fever and extensive suppurations; and three from a spreading gangrene on the surface of the stump. 18 had a hæmorrhage, six from vessels. In nearly the whole, the symptomatic fever was violent; the No. 4091 startings and spasms frequent; the suppuration large; the surface of the wound extensive; and in all the first dressings were painful. In most of them, there was an exfoliation; and in se
stump; and in some the wound remained incurable.

I will not read any account of the operations, but were I to do so you would not be surprised at the results being poor. If along with this you consider the material upon which the operations were performed and the enormous disadvantages under which the surgeon laboured you would wonder that any patients at all recovered. Of course there was no anæsthetic, and the patient, fearing the pain of operation, would put it off till he could go on no longer. The hospitals also were not all that could be desired. In spite of all this, however, Alanson performed 35 amputations with no mortality. As far as mortality goes these results of Alanson would compare with those of the present time, but the method and ease of recovery would be very different. He himself mentions incidentally a patient's remark "that the first dressing was worse than any part of the operation." Alanson's results were due to individual genius and care and did not at all represent the general results of the surgical community. Unfortunately at that time there was no North of England or other medical society at which Alanson could enunciate principles to enlighten the world he was merely able to do better work than his contemporaries and he wrote a book. Having no microscope he was not in a position to prove by actual demonstration the soundness of his principles, although his results showed the value of his methods. His teaching was in consequence forgotten. Before passing on I should like to quote some of Alanson's observations on hospital management, which will give you some idea of the genius of the man and the difficulties which surrounded the surgeon of those days. He says :

Many hospitals are so tainted by unwholesome effuvia, that they are rather a pest, than a relief to the objects they contain. The following regulations are humbly recommended to the consideration of those, who have the care of hospitals in want of such attention. 1. No ward should be inhabited for a space of more than four months together; for it is impossible to keep a room healthy, that is constantly crowded with diseaserl people; the walls should be scraped, whitewashed and every other necessary means used for the purification of the air, before the
re-admission of patients. 2. The bed-stocks should be made of iron, to prevent the lodgement of vermin and the more easy absorption of putrid matter. 3. The bedding should be more frequently changed, putrid matter. 3. The bedding should be more frequently changed, or materials ot such easy expense, as to admit of their being frequently or materials ot such easy expense, as to admit of their being frequently
changed. 4. Where the hospital is conveniently situated for the changed. 4. Where the hospital is conveniently situated for the purpose, all the patients that are able, should carry out their hedding when the weather permits. 5. On the days of admission, those patients that have inhabited foul ships, jails, cellars or garrets, workhouses or other infected places; or whose clothes are dirty, or suspected to contain vermin, before they are suffered to appear in the ward, should first be stripped, and washed in the warm bath, and afterwards clothed with proper dresses, provided at the expense of the Charity; by which means the evil of importing infection, so detrimental to the salubrity of every hospital, would be greatly remedied.1..... 7. The infected clothes should be baked in an be destroystructed for the purpose; by which all vermin and infection will when they are discharged the Hospital. 8. The patients, when received on the days of admission, should be placed in the wards that have been last ventilated, and not in those, that have been long inhabited, where it may reasonably be presumed, the air is considerably tainted. 9. All incurable or infections cases should be refused admittance; and incurable or infectious cases should be refused admittance; and amongst these should be classed old chronic ulcers of the legs, and
particularly those in which there is great loss of substance, for particularly those in which there is great loss of substance, for
these seldom remained long healed; hence most Hospitals are so these seldom remained long healed; hence most Hospitals are so crowded, that the intention of the Charity is perverted, as the
air is rendered unwholesome. 10. All offensive, gangrenous, or other putrid sores, should be placed in distinct rooms provided for that purpose; and not suffered to taint the whole ward. 11. There should be particular rooms provided for those patients who are the subjects of operations; they should be in the most airy situation, never long inhabited and alternately cleaned and ventilated, as before advised. 12. A Hospital should never be crowded on any account; and always of so large a construction, that some part of the building may at all times be uninhabited, for the purpose of whitewashing, ventilation, \&c. 13. When any person has been afflicted with a putrid disease. or confined to bed for a length of time, let the bed be emptied, and the bed-stocks, the bed, the sheets, and other linen open air, and baked in the oven befnre they are used again. 14. Let the nurses see that every patient's hands and face are washed every morning; and their feet, once a week. 15. Let the nurse of each ward windows in her ward, are not kept open during a stated number of windows in her ward, are not kept open during a stated number of
hours every day. 16. To every infirmary, particularly where the wards hours every day. 16. To every infirmary, particularly where the wards
are crowded, a house in the country, well situated, and at a convenient are crowded, a house in the country, well situated, and at a convenient
distance, should appertain; without such assistance many of distance, should appertain; without such assistance many of the patients must perish, which would be easily and certainly
preserved; and it will be found, (as may without difficulty preserved; and it will be found, as may without difficulty firmary, to provide such an appendix. By such assistance patients may be speedily cured, at a small expense; but, if suffered to remain in the Infirmary, their recovery will either be prevented, or
obtained in a great length of time, at a considerable expense, by the

I The sixth regulation which applies to the dresses need not be given. 
most costly drugs, nutritious diet, \&c.; likewise the house will be crowded with the most miserable objects, to the anxiety of those that crowded with the most miserable objects, to the anxiety of those that attend them, and the exclusion of other patients, who might have been of providing lodgings in the country, at their own expense, for their of providing lodgings in the country, at their own expense, for their patients who have undergone operations; rather than suffer the pain of a disappointment in completing a good cure or seeing their patient languish under a hectic, incurable in a crowded Infirmary. Therefore it is hoped that these considerations will influence the humane Trustees, to provide these conveniences for the poor sufferers.

I think, gentlemen, that although my quotation has been rather a long one, yet it is a most interesting thing to remember that these remarkable suggestions were made 120 years ago by Edward Alanson, surgeon to the Liverpool Royal Infirmary, and I doubt whether they could be improved upon at the present day; we are not yet able to say that all the improvements indicated by him have been accomplished. He was indeed in advance of his time and was very near the truth as it appears to us to-day. The main point that strikes one is the great importance which he evidently attaches to the part played by the air in the spreading of infection. We think less of the air and more of the hands as infection-spreaders. We think less of infection and more of contagion. This seems a small difference, but it is a fundamental difference in principle, which is responsible for nearly all that divides our present work from that of 100 years ago. Owing to our better hospital construction the want of ventilation, \&c., has been removed from our list of enemies and we can confine our attention to the dangers of contact. So much for the first period. method of treatment. My chief said that he thought this case would be a suitable one on which to try the new method of treatment, and it was arranged that the operation should be performed upon the following day. We all forthwith went down into the post-mortem room and practised this new operation. 'There was one gimlet which pierced the bone in a marvellously easy way, in a way that none of the others would. The surgeon naturally said, "We will use that one to-morrow," and we did. The operation was performed on the following day in a most masterly fashion, under a clond of carbolic spray and (according to the notes) "with the strictest antiseptic precautions." Things went wrong, however, and the man died from septicæmia. The gimlet had killed him. But the antiseptic system and the new operation were blamed at the time. We have learned much since then, and it seems remarkable to us now that anyone could be so blind; but it is well to remember that the men who appear to us so blind were the leaders of the profession and the most advanced men of the time, and we must expect to appear just as blind to the next generation.

We are now passing from the antiseptic period to the non. antiseptic or aseptic period, and if we do not attain the results that have been attained by some we should not at once blame the system, but carefully criticise our own technique and remember the story of the gimlet.

It is hardly necessary to say that when $I$ use the term " aseptic surgery" I use it in the sense of being without antiseptics. I do not care for the term, but I do not know a FiG. 1.

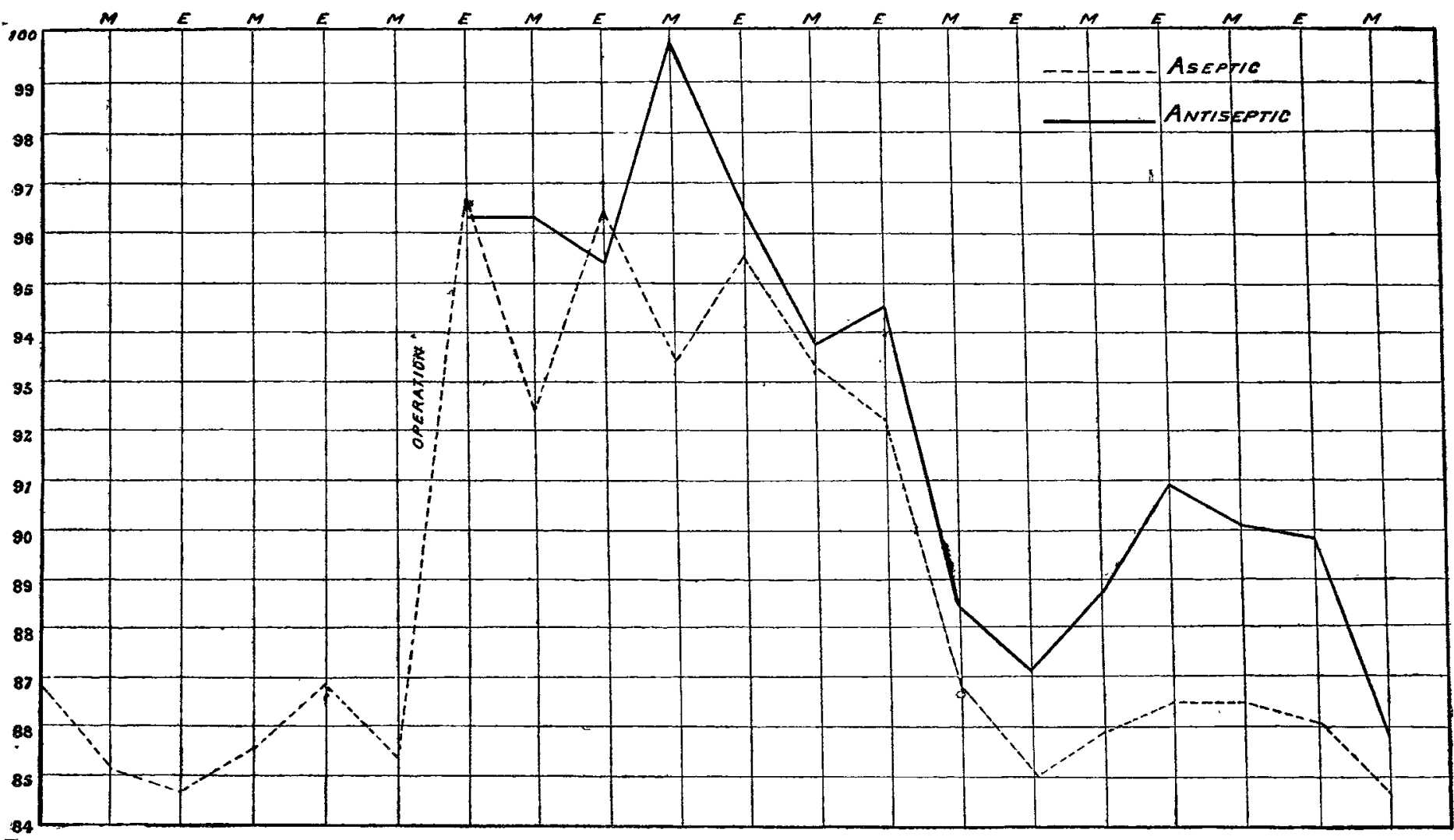

Mean pulse chart of 80 cases of abdominal section-40 aseptic and 40 antiseptic.

The second period, or the antiseptic stage, is so recent that it is not necessary to recall what is known to everybody. In the short period of 20 years or little more a complete revolution in surgical methods has taken place, and it would hardly be exaggeration to say that in that time we have passed from night into day. For although there must be much to learn and to simplify in the future, yet when we compare the methods of to-day with the methods of 20 years ago we may almost say that we are now already in the full light of noonday. I well remember an incident which happened when $I$ was a dresser, not such very remote ages ago. It made a great impression on my mind at the time, and $I$ have often pondered over it since. To us to-day it sounds like a story of the Middle Ages. A man was brought into hospital having fractured his patella. At about this time Mr. Lister had been suggesting wiring together the fragments as a better unless we borrow a term from medicine and speak of "prophylactic" or "preventive" surgery. The term "preventive" would indicate the principle which underlies our present practice. There always seems to have been a fascination for the surgeon to put something into his wound to make it heal better. In the pre-antiseptic days at one time it was the fashion to fill the wound with boiling oil, at another the wound was stuffed with dry lint and freely dredged with flour, and many other devices were employed. In the antiseptic period wounds were donched and swilled with antiseptics and sometimes filled up with iodoform. In the aseptic method there is nothing put into the wound to irritate it or to help it to heal ; the object is to keep out all that is detrimental to healing.

Aseptic surgery is a stage onwards towards the goal of perfect surgery. We all hailed antisepsis, and now we should all hail asepsis. Antisepsis naturally came first and 
was the means by which we were able to advance the art of surgery so enormously that satisfaction and gratification beyond the dreams of the most sanguine were gradually realised. This satisfaction has been so great that some are even still complacent with surprise at the marvellous results. However, after this first surprise at unexpected successes, there has risen gradually a feeling that perhaps there may be something even better still, something to criticise even in the best results yet attained by the antiseptic method, marvellous as these are when we compare them with the results of a short time back.

And so we come to the third or aseptic stage, and there is no doubt that this is a decided step in advance of the antiseptic stage and the advance is measured by the ease of recovery after operations. Of course, there has been gradual and decided improvement since the antiseptic stage commenced, and the results at the end of the antiseptic stage became so good that we cannot expect a startling improvement at the commencement of the aseptic stage similar to that at the commencement of the antiseptic stage. Further, we must remember that the actual change is only comparatively slight from the end of the antiseptic method to the commencement of the aseptic method. The chief difference is a difference in principle indicated by the term "preventive." However, in spite of all this I think that there is a distinct improvement in the results that I have obtained by the aseptic method over anything that I have obtained by the antiseptic method.

I do not propose to enter into minute details of my present method of operating, but I will merely say that I now use no antiseptics whatever during operations. When the operation commences all antiseptics are laid aside, and where formerly I used antiseptic lotions and antiseptic dressings I now use sterile water and sterile dressings. I do not allow any antiseptics to get into my wounds. The skin of the patient and the hands of the operator and assistants are prepared most carefully with antiseptics, but as soon as the operation commences no further use is made of antiseptics. The method of hand-cleaning which I adopt is the permanganate and oxalic acid method. This method is most satisfactory and has stood some very severe tests that I have subjected it to. Cleaning hands by this method certainly takes some time-about 20 minutes-but I am sure that it is time well spent and that you are amply repaid for it. In my operations we take every preventive precaution that we can think of to ensure asepsis, but as these details would necessarily be tedious I shall not allude to them further ; in place of detail I will express a sentiment which is, I think, true and useful. The success of the operation depends upon the preparations for its performance--that is, upon the completeness and efficiency of the prophylaxis. The comparison which I have made between a series of antiseptic operations and a series of aseptic ones certainly has been all in favour of the aseptic series.

In order to show the results of the above-mentioned series graphically I have constructed two composite charts, and my thanks are due to my house surgeon, Mr. O. T. Williams, for the help which he has given me in drawing these up.

The charts (Figs. 1 and 2 ) represent 80 cases of abdomiral section-40 antiseptic operations and 40 aseptic operations. The black line marks the antiseptic series and the broken line the aseptic series. The charts were made in the following way. The pulse and temperature in each case were recorded twice daily, at 10 A.M. and at 6 P.M. The record on the composite chart was obtained by adding together the records on the individual charts of each series and dividing by 40 to get the mean. The mean pulse and the mean temperature in each series are given on the charts for three days before and a week after operation. (In the antiseptic series there is no record of pulse before operation.) You will notice that the broken line, representing the aseptic series, is always inside the black antiseptic line; this denotes an easier recovery after operation in the aseptic series. In looking at these charts you may be inclined to say that there is a greater rise in pulse and temperature than you would expect and that your own results would be better than those which I show you, but you must remember that these composite charts include all cases, bad and good, easy or difficult, and this is the mean of the whole lot. I could show you individual charts in the antiseptic or aseptic series in which there was no rise of pulse or of temperature whatever, but this is beside the point; what I want to show is that there is an average improvement in the aseptic series and that it is an improvement on results which will not compare badly with ?

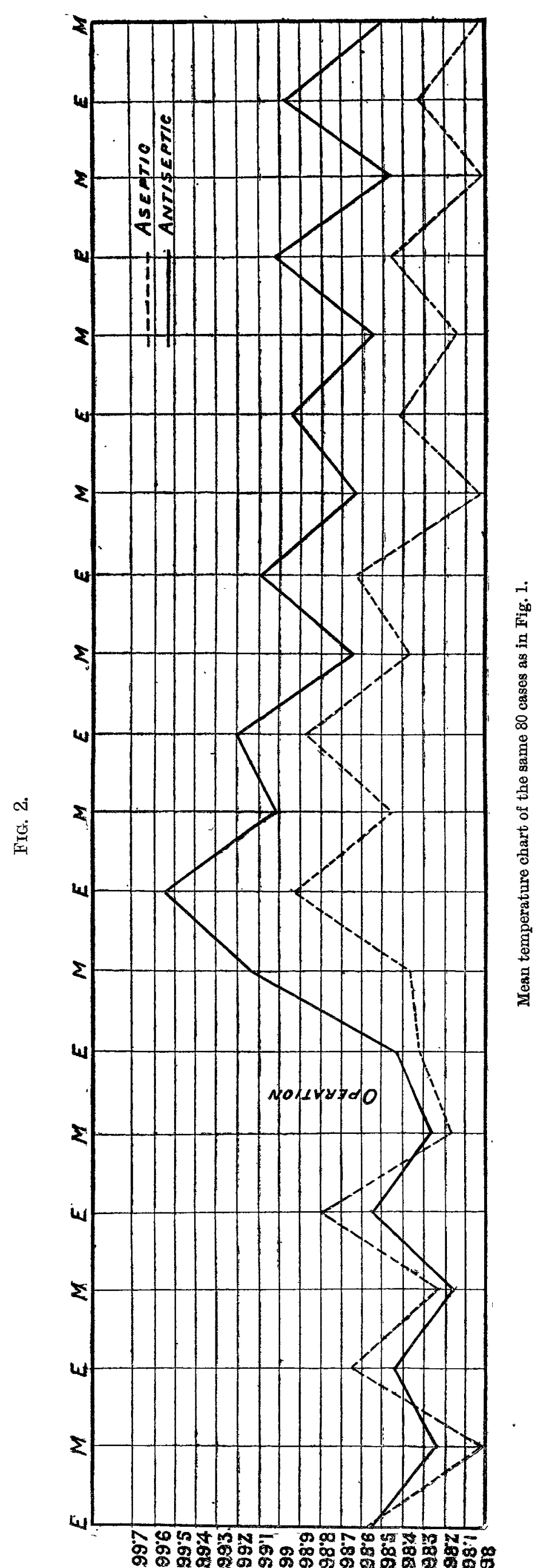


the results of other operators. I consider that my antiseptic composite chart is very good, but the aseptic chart is better. You will notice that in both series on the fourth morning after operation the patient is well; the pulse and temperature have returned to the normal. There are other points which I cannot show you graphically but of which I feel fully convinced in my own mind. There have been less pain and less trouble from flatulence after operation, and I think that the scars are less inclined to be keloid. I have no doubt that the general comfort of the patient has been increased. These results have been most gratifying to me, and in presenting them to you I have endeavoured to avoid anything like high colouring. I trust that I have not rendered them colourless, but Pope's lines have all along been in my mind :-

"To observations which ourselves we make
We grow more partial for the observer's sake."

\section{An oprening gdodess}

ON

\section{THE ART OF CLINICAL MEDICINE AND ITS TECHNIQUE.}

Delivered before the Students' Medical Society of the Leeds Medical School on Oct. 18th, 1901,

\section{By WILLIAM EWART, M.D. Cantab.,} F.R.C.P. LoND.,

SENTOR PHYSICIAN TO ST. GEORGE'S HOSPITAL AND TO THE BELGRAVE HOSPITAL FOR CHILDREX.

Gentlemen, - My sense of the honour of your invitation to address you to-night, if it can be equalled by anything, could only compare with the pleasure of finding myself among you in the congenial and invigorating atmosphere of a students' debating society, an old student among those of youthful aspirations and promise, for a semi-confidential talk on matters of intimate concern to us all. To this society, among all other students' medical societies, it is now my privilege to wish every success. The secret of their usefulness and attraction is largely the same as that which facilitates the successful study of clinical medicine and which is also fundamental to the position and dignity of the medical confraternity-collaboration and mutual help : every man contributing his share and ever ready to help his fellow in the joint service of suffering humanity. There is another feature in students' medical societies which suits our subject-it is their universality. Clinical medicine itself is all-embracing. It claims not only a relationship with various kindred sciences but also their constant service. All the work of this prosperous and progressive medical school practically tends to one end, which in my experience has been thoroughly fulfilled-the making of good clinical men. Although, therefore, in offering any clinical advice in this place I feel guilty of bringing coals to Newcastle, your liberality will discern that this fault is inherent to my theme rather than to my intention.

On the subject of clinical art I cannot spare you the infliction of a few true aphorisms. It was the art of clinical medicine which drew from the greatest of physicians the pathetic utterance equally descriptive of all human art"Ars longa, vita brevis." To the present day it remains the longest of arts and therefore its study must claim the largest share of our time.

"The ideal is the soul of art." This aphorism, though it might seem to be hardly opportune, underlies the whole of our practical purpose to-night. It declares our belief that clinical medicine is eminently progressive and that a brief consideration of some of its tendencies and some of the conditions of its future advance is, perhaps, a pardonable digression. Imagination, that humble "occasional helper" of science, is art's principal handmaid; and it may not be altogether idle to dream of those possibilities which are not yet fully within the reach of this generation.

"Ars imitatio naturce." This is above all others the clinical aphorism. Half the secret of the clinical art is the correct observation of nature, the other half its successful imitation. But I must not dwell upon that important topic, but at once draw your attention to another aphorism most intimately connected with the purpose of this address"All art consists of the technique and of the production."

The work of art brings into free play man's highest intellectual and physical attributes; but only provided they have been liberated by patient practice from all mechanical struggle with the accidents of technique. 'These two components of art are not only distinct but are in some respects in glaring contrast. Nothing could be more prosaic, mechanical, and laborious than the study of technique which is to furnish the ideal with its incarnation. All this is strikingly exemplified in the study of clinical medicine, and the distinction between the technique and the performance is one which it will repay you to grasp at the earliest stage.

I have dwelt upon points of resemblance. In one respect clinical medicine differs from all other arts. Perfection such as is achieved by other artists is denied to us. Our task almost passes the wit of man. It is that of remedying damage and disturbance in a machine of unimaginable complexity. A few hard facts are supplied to us by the sciences; and in addition to these, our scientific facts, there are the so-called great principles of medicine, most of which are empirical postulates and cannot take rank with experimental evidence, but nevertheless are of immense practical value. These are our assets; but when the balance is struck the sum of our actual knowledge is vastly inferior to that of the unknown and perhaps of the unknowable. In other words, our art is an amazing combination of strict knowledge and of absolute ignorance, of minute accuracy and of immense vagueness-it is an art of sciences and an art of the unknown.

But there is a greater inconsistence. Though we confess our ignorance we are as practitioners not allowed to plead it as an excuse. Where life is trembling in the balance something must be done, and our patient expects this something to be the right thing. To act for the best in spite of pervading ignorance is indeed an art. Let it, then, be no slur upon clinical medicine that it is eminently versatile, that it looks all around for help, and that, when it is deserted by science, in its distress it should call imagination to its aid and should not shrink from consulting empiricism. Empiricism and science are a powerful combination. Traditional empiricism-the accumulated experience of countless generations of untrained observers-although hardly as trustworthy as the unthinking instinct of animals, still is a mine of treasure which has only begun to be worked with the searchlight of science. Happily in the perplexity of many counsels we fall back upon the great clinical precept, "Non nocere," and though science may fail us there is one ever-trusted guide, "Imitatio nuturce." The methods adopted by nature are our standard and the test of the safety of our tactics. In spite, then. of our ignorance our treatment may still be of the best if we can succeed in reading nature, not only in a general sense, but nature as she presents herself in the individual patient, and in acquiring that insight which the laity so aptly describe as a knowledge of the patient's constitution.

\section{Medical Education, Past, Present, and Future.}

If I may use the privilege of this debating society to discuss debateable questions, the following considerations may be of interest and perhaps of indirect service.

There are two prominent signs of the times. The first is the rapid and irresistible expansion of science in clinical medicine; to this the public mind has been effectually awakened, and patients not only desire but claim to be treated with all the resources of science. This tendency in therapeutics is reflected in medical education ; and practical shape is now being given to it by the growth of the idea of the clinical laboratory, probably the most important element in the clinical system of a near future. No less significant is the other contemporary innovation-the post-graduate system, which symbolises the need which is felt for more clinical instruction. The extraordinary sacrifices made for the sake of further clinical opportunities by members of an overworked profession illustrate the urgency of that need. These two tendencies give special prominence to the prevailing dissociation between the science course and the clinical course to which further reference will be made.

History is full of teachings. Looking back 150 years ago, prior to the birth of modern science, we find the simplest expression of medical education on the pattern of the mediæval trades and guilds - a practical training beginning at an early age-and a course of theory as a finish for maturer years. 